\title{
Dynamic behaviour of photosynthesis-irradiance curves determined from oxygen production during variable incubation periods
}

\author{
M. F. Macedo ${ }^{1, *}$, J. G. Ferreira ${ }^{1}$, P. Duarte ${ }^{2}$ \\ ${ }^{1}$ Dept of Environmental Sciences \& Engineering, Faculty of Sciences and Technology, New University of Lisbon, \\ P-2825 Monte de Caparica, Portugal \\ ${ }^{2}$ Dept of Sciences \& Technology, Fernando Pessoa University, Praça 9 de Abril 349, P-4200 Porto, Portugal
}

\begin{abstract}
Production and consumption of oxygen were analysed in phytoplankton populations using a fast biomass-concentration technique. The variation of productivity with irradiance was studied using different incubation periods, from minutes to hours. The influence of the exposure time on the photosynthesis-irradiance $(P / I)$ curve parameters was analysed. The results show that dissolved oxygen concentration in the water does not increase linearly with time and that $P_{\max }^{B}$ (maximum biomassspecific production rate and $I_{\text {op }}$ (optimal light intensity) are time-dependent. Exponential and linear expressions were proposed to describe $P_{\max }^{B}$ and $I_{\mathrm{op} 1}$ as a function of time. A model was built to investigate the importance of static (steady-state) vs dynamic (time-dependent) simulation in the prediction of phytoplankton production under different light intensities. The results show the importance of using dynamic expressions for the $P / I$ relationship, especially in a mixed water column.
\end{abstract}

KEY WORDS: Biomass concentration - Phytoplankton productivity - Short incubation periods - Oxygen method $\cdot$ Ecological model

\section{INTRODUCTION}

The photosynthesis-irradiance $(P / I)$ relationship is fundamental to estimates of phytoplankton productivity. Several mathematical models have been proposed for its description (e.g. Steele 1962, Jassby \& Platt 1976 Platt et al. 1980, Falkowski \& Wirick 1981, Mergard et al. 1984, Eilers \& Peeters 1988, Pahl-Wostl \& Imboden 1990, Janowitz \& Kamykowski 1991). These models can be divided into static and dynamic according to whether they are steady-state or time-dependent.

The dependence of photosynthesis on light intensity may be altered by variations recently experienced by the organisms involved. The major source of these fluctuations is vertical motion (Denman \& Gargett 1983), which will not only maintain the phytoplankton population in the mixed layer, but will also have a profound effect on photosynthetic rates.

\footnotetext{
•E-mail:mfmd@helios.sj.fct.unl.pt
}

Short-term (minutes to hours) variation in phytoplankton physiology is a general problem in the measurement and prediction of primary productivity in mixed layers in estuaries. Whereas on a continental shelf, with a photic zone of $50 \mathrm{~m}$ and a vertical diffusion coefficient of about $50 \mathrm{~cm}^{2} \mathrm{~s}^{-1}$, a phytoplanktonic cell crosses the photic zone and therefore the full gradient of irradiance in the mixed layer in about $3 \mathrm{~d}$, the same range of irradiance is crossed in $13 \mathrm{~min}$ in an estuary with a photic depth of $2 \mathrm{~m}$ (Macintyre \& Geider 1996). In turbid estuaries with shallow waters the photic zone may be less than $0.5 \mathrm{~m}$ deep, and the phytoplankton may be mixed through most of the photic zone in 3 to $4 \mathrm{~min}$ (MacIntyre 1993). Several workers have studied the effect that fluctuations in the light field have on productivity (Marra 1978a, b, Gallegos \& Platt 1985, Yoder \& Bishop 1985, Randall \& Day 1987, Mallin \& Paerl 1992, Franks \& Marra 1994, MacIntyre \& Geider 1996). There is some evidence that phytoplankton can maintain high rates of photosynthesis during the first minutes after initial exposure to sat- 
urating or inhibiting irradiance (Harris \& Lott 1973. Harris \& Piccinin 1977, Marra 1978a, b). The major concern is that photoinhibition is a time-dependent process (Kok 1956, Takahashi et al. 1971, Harris \& Lott 1973). During mixing, the residence time of phytoplankton in the surface layer, where photoinhibition may occur, is of the same order of magnitude as the time over which phytoplankton can maintain high rates of photosynthesis before photoinhibition becomes prevalent. It is also known that long-period incubations ( $>2$ h) may lead to underestimation of the photosynthetic rates (Lewis et al. 1984, Gallegos \& Platt 1985, Pahl-Wostl \& Imboden 1990). Therefore the classical way of measuring primary productivity by the light/dark bottle technique, and the use of the results obtained to estimate the $P / I$ curve parameters, might lead to overestimation of photoinhibition.

It is well established that the parameters used in the productivity-light curve change as a result of adaptation at different time scales, suggesting that the dynamic behaviour of the $P / I$ curve parameters should be included in ecological models.

The problem of determinating the short-term processes in phytoplankton physiology is also a problem concerning the methods used to estimate the photosynthetic and respiration rates. The ${ }^{14} \mathrm{C}$ method allows the measurement of carbon fixation even at very low production rates, but artifacts which may arise when using this method (measuring gross or net photosynthesis, use of radioactive material, differential uptake of ${ }^{14} \mathrm{C} /{ }^{12} \mathrm{C}$ ) are still a matter of controversy (Peterson 1980, ICES 1996). The advantage of the oxygen method is that net primary production (NPP), gross primary production GPP) and respiration (R) may be determined. One of the disadvantages is that heterotrophic respiration is also included in the measurement. More importantly, the sensitivity of this method is usually too low to detect oxygen changes under short $(<1$ h) incubation times. This question may be addressed by concentrating the phytoplankton biomass, in order to reduce the incubation period by increasing the consumption/production of carbon/oxygen (Duarte \& Ferreira 1997).

Experiments using concentrated phytoplankton samples have been performed by other authors to measure the photosynthetic and/or respiration rates from natural populations (e.g. Pomeroy \& Johannes 1968, Harris \& Piccinin 1977). The methodology of concentration found in the literature is very variable, from the Dodson \& Thomas (1964) method, through centrifugation (e.g. Iwakuma \& Yasuno 1983), to the use of concentrating nets. The first 2 methods have laborious procedures and/or allow only the concentration of small volumes. With the third method, nets are used to quickly filter large volumes of water generally for taxonomic studies. The main disadvantages of the nets are the potential distortion of species composition due to phytoplankton selectivity, clogging in turbid waters, damage to some organisms (particularly naked flagellates; UNESCO 1978) and inclusion of zooplankton in the sample. In the present work, an alternative phytoplankton concentration net was developed to concentrate large volumes of phytoplankton rapidly without concentrating the zooplankton, clogging or damaging the organisms. This net was tested in a very turbid water column.

Data collected by Marra (1978a, b), Marra \& Heinemann (1982) and Cullen \& Lewis (1988) have been the basis of several models that relate photosynthesis to fluctuating light intensity (Neale \& Marra 1985, PahlWostl \& Imboden 1990, Franks \& Marra 1994). New data on the time dependence of the $P / I$ relationship are presented and a different model for this relationship is proposed.

The objectives of the present work were the following:

(1) to develop a technique that allows fast phytoplankton pre-concentration and to explore the potential for short-term photosynthetic measurements using the oxygen method;

(2) to use this technique to study short-term P/I relationships;

(3) to investigate the influence of the exposure time on the $P / I$ curve parameters;

(4) to develop a primary production model that takes into account the dynamic behaviour of the $P / I$ curve parameters.

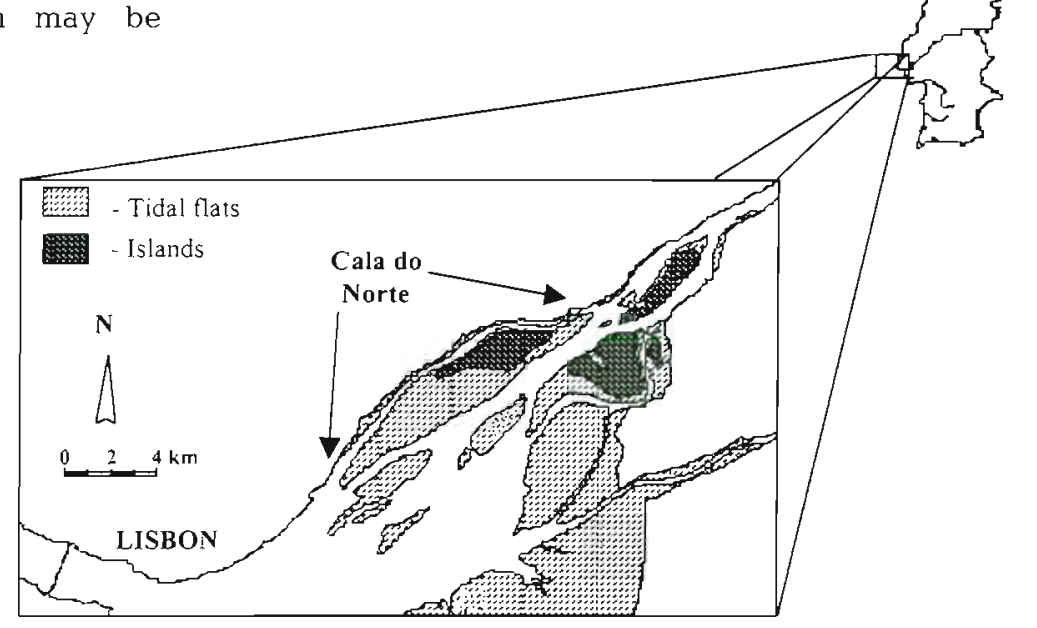

Fig. 1. Cala do Norte of the Tagus Estuary, Portugal 


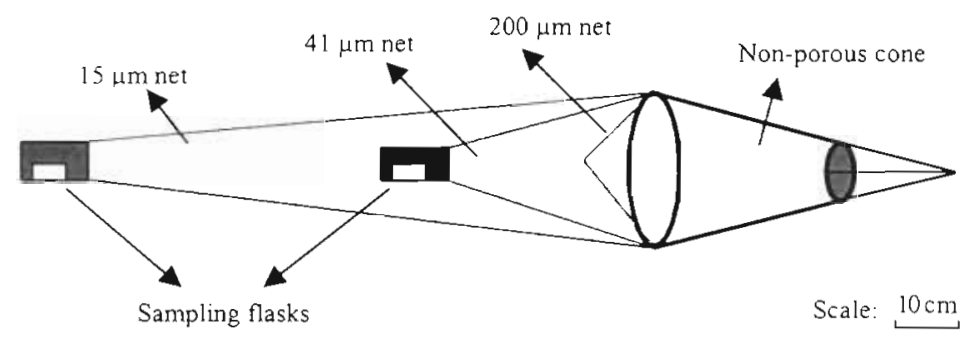

Fig. 2. Towing net used to concentrate phytoplankton

\section{MATERIAL AND METHODS}

Study area. The Tagus Estuary (Portugal) (Fig. 1) is a large estuarine ecosystem (surface area $320 \mathrm{~km}^{2}$ and mean volume $1900 \times 10^{6} \mathrm{~m}^{3}$; Ferreira \& Ramos 1989). The tidal amplitude ranges from less than $1 \mathrm{~m}$ to $4 \mathrm{~m}$ during a spring-neap cycle. The Tagus River is the main source of freshwater to the estuary, with a modal discharge of about $400 \mathrm{~m}^{3} \mathrm{~s}^{-1}$. This corresponds to an estuary number of less than $1 \%$, indicating that the system should in general be vertically well mixed, which has been verified in the field, although the circulation is not laterally homogeneous (Carvalho et al. 1997).

The data were obtained in a channel of the Tagus Estuary, with a mean depth of $2.3 \mathrm{~m}$. The salinity ranges from 0 to $32 \mathrm{psu}$ and is strongly influenced by the semi-diurnal and fortnightly tidal cycles. The water is very turbid, with annual values of suspended matter ranging from 45 to $120 \mathrm{mg} \mathrm{l}^{-1}$.

Sampling and treatment. The experiments were performed over a period of $6 \mathrm{wk}$ (May to July 1996) when the biomass of planktonic algae was consistently high, with chlorophyll a ( $\mathrm{chl}$ a) concentrations varying from 8 to $47 \mathrm{mg} \mathrm{m}^{-3}$. Surface water samples for the determination of physical and chemical parameters and phytoplankton biomass were taken hourly over 3 to $5 \mathrm{~h}$, depending on the experiment. Temperature, oxygen, salinity and light extinction were measured in situ. The phytoplankton biomass was concentrated using a net built with the aim of rapidly concentrating large volumes of phytoplankton in a turbid water column. This net consisted of 3 filtering cones with different gauze $(200,41$ and $15 \mu \mathrm{m})$ nested inside each other: the first, with $200 \mu \mathrm{m}$, did not have a plankton-collecting vessel and was used to restrict the input of detritus and zooplankton (Fig. 2). The water inflow was reduced by the small diameter of the mouth ring and by the non-porous textile cone in front of the net. This modification increased the ratio between the filtering area and the mouth area and reduced clogging.

After towing, the net was washed with estuarine water that had been previously filtered through a $15 \mu \mathrm{m}$ filter. The plankton was collected from sampling flasks connected to the 41 and $15 \mu \mathrm{m}$ nets. The filtered water $(<15 \mu \mathrm{m})$ was also used as a control sample. All samples were kept in darkness (4 h) until incubation. The time spent by the phytoplankton cells in the dark was identical in all the experiments.

Species determination. Concentrated, non-concentrated and control samples for species determination were preserved with Lugol's solution. Phytoplankton cells were counted by the Utermöhl technique. Cell abundance data were transformed into relative values of species biomass, by applying the Taguchi equation (Taguchi 1976) using cell volumes reported in the literature (Jørgensen et al. 1991).

Incubation procedures. Samples were incubated in the laboratory using light provided by $1500 \mathrm{~W}$ tungsten halogen lamps. Heat produced by the lamps was dissipated using a cold water flow system. Light intensity ( 0 to $1445 \mu \mathrm{E} \mathrm{m}^{-2} \mathrm{~s}^{-1}$ ) was measured with a LI-COR underwater cosine quantum sensor and attenuation was achieved by means of grey PVC nets. Preservation of the spectral characteristics was verified by spectral analysis (Fig. 3). Three replicate Winkler flasks (65 ml), volume calibrated to $0.01 \mathrm{ml}$, were incubated for each light intensity, for periods ranging from 15 to $240 \mathrm{~min}$.

Chemical analyses. Concentration of oxygen was measured in replicate bottles by titration with the azide modification of the Winkler method (Phillips 1973). A microburette was used to titrate the whole contents of the Winkler bottles (Carritt \& Carpenter 1966, Strickland \& Parsons 1972). Chl a concentration was determined flu-

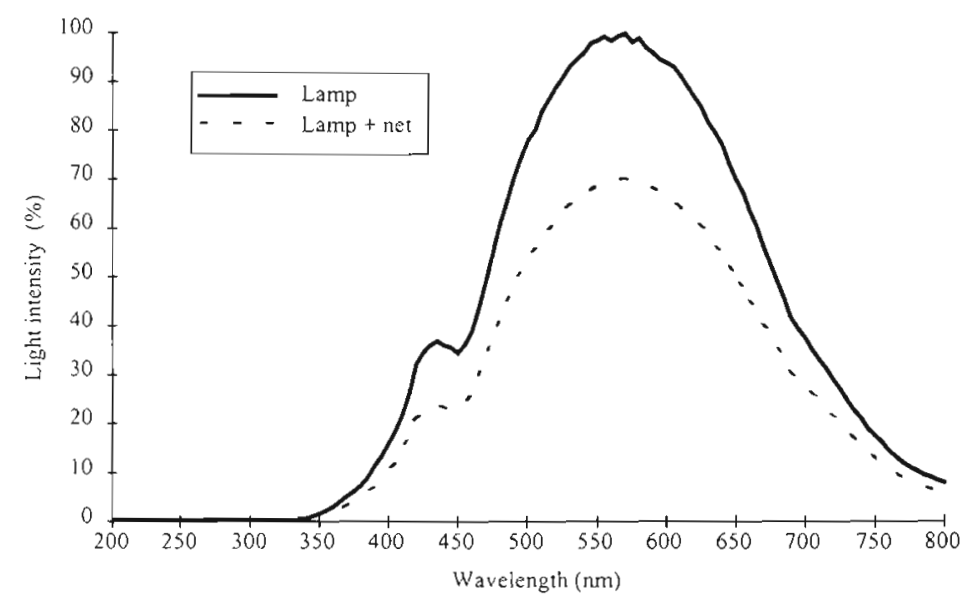

Fig. 3. Emission spectra of the tungsten halogen lamp: direct and through the PVC net 
orometrically by the method of Yentsch \& Menzel (1963) as modified by Holm-Hansen et al. (1965).

Primary production determination. Productivity and respiration were measured from oxygen differences by the light-dark bottle technique. A photosynthetic quotient of 1.2 and a respiratory quotient of 0.8 were used in the conversion of oxygen to carbon according to Vollenweider (1974) and Geider \& Osborne (1989). Three different experiments were performed for primary production determination.

The purpose of the first experiment (Expt I) was to test whether the rate of oxygen production or respiration was affected by the pre-concentration technique of the phytoplankton biomass. A concentrated phytoplankton sample was diluted with a control sample to obtain different concentrations. All samples were incubated at $100 \mu \mathrm{E} \mathrm{m}^{-2} \mathrm{~s}^{-1}$ for a period of $240 \mathrm{~min}$.

The aim of Expt II was to study the $P / I$ relationships in a natural phytoplankton sample. The incubation was performed with a non-concentrated sample but some phytoplankton was also concentrated for species determination. The samples were incubated for $3 \mathrm{~h}$ at light intensities ranging from 0 to $1280 \mu \mathrm{E} \mathrm{m}^{-2} \mathrm{~s}^{-1}$. Since the choice of different $P / I$ models frequently leads to different estimated parameter values of the $P / I$ curve (Frenette et al. 1993), 3 different models were used (Table 1), The superscript $B$ denotes that $P / I$ characteristics were calculated per $\mathrm{mg} \mathrm{chl}$ a.

Some of the $P / I$ curve parameters cannot be derived directly from the equations shown in Table 1, therefore some additional calculations were performed. The $I_{\text {opt }}$ (optimal light intensity) and $P_{\max }^{B}$ (maximal production rate) can be directly obtained from Steele's (1962) equation. The initial slope of the light saturation curve $(\alpha)$ can be determined by

$\alpha=\left.\frac{\mathrm{d} P^{B}}{\mathrm{~d} I}\right|_{I=0}=P_{\max }^{B} \frac{\mathrm{e}}{I_{\mathrm{opt}}}\left[\mathrm{mgC}(\operatorname{mgchl} a)^{-1} \mathrm{~h}^{-1} \mu \mathrm{E}^{-1} \mathrm{~m}^{2} \mathrm{~s}\right]$

Table 1. Equations used to calculate the photosynthesisirradiance $(P / I)$ parameters. $I$ is the light intensity, $I_{\mathrm{opt}}$ is the optimal light intensity, $P_{\operatorname{mix}}^{B}$ is the maximal biomass-specific production rate, $\beta$ is the photoinhibition parameter and $\alpha$ is the initial slope of the light saturation curve

\begin{tabular}{|c|c|}
\hline Equation & Type \\
\hline Steele (1.962) $\quad P^{B}=P_{\max }^{B} \frac{I}{I_{\mathrm{opt}}} \mathrm{e}^{\left(1-\frac{1}{I_{\mathrm{opt}}}\right)}$ & Empirical \\
\hline 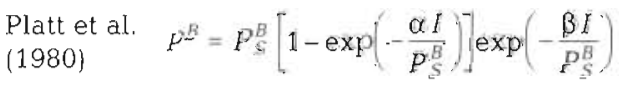 & Empirical \\
\hline $\begin{array}{l}\text { Eilers \& Peeters } \quad P^{E}=\frac{I}{a I^{2}+b I+c} \\
(1988)\end{array}$ & Rational \\
\hline
\end{tabular}

The ratio $P_{\max }^{B}: \alpha$ is identical to the parameter $I_{k}$ defined by Talling (1957) and corresponds to the point at which the linear part of the light-saturation curve intersects the plateau.

The parameters $\alpha_{1} \beta$, and $P_{S}^{B}$ directly result from the Platt et al. (1980) model. According to the authors the $I_{\text {opt }}$ parameter can be obtained by

$$
I_{\text {opt }}=\frac{P_{S}^{B}}{\alpha} \ln \left(\frac{\alpha+\beta}{\beta}\right) \quad\left(\mu \mathrm{E} \mathrm{m}^{-2} \mathrm{~s}^{-1}\right)
$$

and substituting Eq. (2) in the Platt et al. (1980) equation (Table 1) gives the maximum productivity

$$
P_{\max }^{B}=P_{S}^{B}\left[\frac{\alpha}{\alpha+\beta}\right]\left[\frac{\beta}{\alpha+\beta}\right]^{\beta / s}\left[\operatorname{mgC}(\operatorname{mgchl} a)^{-1} \mathrm{~h}^{-1}\right]
$$

When the photoinhibition parameter $(\beta)$ tends to zero, $P_{S}^{B}$ tends to $P_{\max }^{B}$, that is $P_{\max }^{B}$ and $P_{S}^{B}$ coincide if there is no inhibition.

By differentiating the Eilers \& Peeters (1988) model (Table 1) the parameters $\alpha, P_{\max }^{B}$ and $I_{\text {opt }}$ can be expressed as a function of the $a, b$, and $c$ parameters:

$$
\begin{aligned}
\alpha & =\frac{1}{C} \\
I_{\mathrm{opt}} & =\sqrt{\frac{c}{a}} \\
P_{\max }^{B} & =\frac{1}{b+2 \sqrt{a c}}
\end{aligned}
$$

and, according to the Eilers \& Peeters, the inverse equations are

$$
\begin{gathered}
a=\frac{1}{\alpha I_{\mathrm{opt}}{ }^{2}} \\
b=\frac{1}{P_{\max }^{B}}-\frac{2}{\alpha I_{\mathrm{opt}}} \\
c=\frac{1}{\alpha}
\end{gathered}
$$

In the last experiment (Expt III) 3 replicates of concentrated samples were incubated at different light

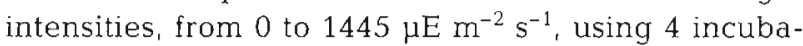
tion periods: $15,45,90$ and $180 \mathrm{~min}$. The influence of exposure time on the $P / I$ curves and parameters was determined. The maximum rate of photosynthesis, $P_{\max }^{B}$, and the optimal light intensity, $I_{\text {opt }}$, were described as time-dependent according to the results found in this experiment.

Model development. A productivity function dependent on light intensity and incubation time, $P(I, t)$, was developed from the Eilers \& Peeters model in order to account for the dynamic aspects of the $P / I$ relationships. A simple mathematical model was built using this productivity function, and assuming a respiration rate constant over the time equal to the value deter- 
mined experimentally. The only biological state variable was phytoplankton and other processes, such as nutrient or temperature limitation, were not considered. Primary productivity modelling was carried out by means of static and dynamic formulations. The only difference between these 2 models is the definition of the productivity function. In the dynamic model the function $P(I, t)$ was used and the parameters changed as a function of time. In the static model the Eilers \& Peeters (1988) $P(I)$ function was used and the parameters remained constant over the simulation period. A time step of $0.1 \mathrm{~min}$ was used in the simulations. Productivity was expressed as $\mathrm{mg} \mathrm{O}_{2}(\mu \mathrm{g} \mathrm{chl} \mathrm{a})^{-1} \mathrm{~min}^{-1}$ and the parameter $\alpha$ was used to calibrate the model.

\section{RESULTS AND DISCUSSION}

A summary of the physical and chemical parameters and chl a concentration determined during sampling is presented in Table 2 . The chl a concentration observed in the field during these experiments was consistently high, which can be related to the sampling season (spring-summer). Data from previous studies (Moita 1982, Macedo 1997) reported that phytoplankton biomass in the same area can range from 0.1 to $39 \mathrm{mg}$ chl $a \mathrm{~m}^{-3}$.

The concentration procedure allowed the concentration of the phytoplankton biomass from a sample with high concentration of suspended particulate matter. It took about $4 \mathrm{~h}$ to collect volumes of 5 to $10 \mathrm{l}$ of concen-

Table 2. Summary of the physical and chemical parameters and chl a concentration determined for the sampling dates. nd: not determined

\begin{tabular}{|lccccc|}
\hline $\begin{array}{l}\text { Date } \\
(1996)\end{array}$ & $\begin{array}{c}\text { Water } \\
\text { temp. } \\
\left({ }^{\circ} \mathrm{C}\right)\end{array}$ & $\begin{array}{c}\text { Dissolved } \\
\text { oxygen } \\
\left(\mathrm{mg} \mathrm{O}_{2} \mathrm{l}^{-1}\right)\end{array}$ & $\begin{array}{c}\text { Salinity } \\
\text { (psu) }\end{array}$ & $\begin{array}{c}\text { Extinction } \\
\text { coeff. }(k) \\
\left(\mathrm{m}^{-1}\right)\end{array}$ & $\begin{array}{c}\text { Chl } a \\
\left(\mathrm{mg} \mathrm{m}^{-3}\right)\end{array}$ \\
\hline May 20 & 16.5 & 6.2 & 0 & 4.86 & 7.7 \\
May 20 & 16 & 6.8 & 0 & 6.8 & 13.1 \\
May 20 & 16 & 7.2 & 0 & 6.8 & 14.3 \\
May 20 & 16 & 6.9 & 0 & 6.8 & 13.3 \\
May 20 & 16 & 6.9 & 0 & 5.7 & 10.6 \\
Jun 15 & 24 & nd & nd & nd & 46.6 \\
Jun 19 & 23 & 4.5 & 21 & 3.4 & 22.8 \\
Jun 19 & 23.5 & 4.5 & 16 & 3.4 & 14.6 \\
Jun 19 & 25 & 5.2 & 10.5 & 4.25 & 16.9 \\
Jun 19 & 25 & 5.6 & 8.5 & 4.86 & 17.8 \\
Jun 19 & 25 & 6.0 & 8.0 & 4.86 & 19.0 \\
Jul 2 & 21.5 & 8.5 & 24.5 & 6.8 & 21.7 \\
Jul 2 & 22 & 8 & 19 & 5.7 & 23.6 \\
Jul 2 & 22.5 & 8 & 9.5 & 6.8 & 19.9 \\
Jul 2 & 23.5 & 7.8 & 8 & 5.7 & 19.1 \\
Jul 2 & 24.5 & 7.5 & 14 & 4.86 & 23.4 \\
Jul 2 & 24 & 5.8 & 19 & 4.25 & 27.5 \\
\hline
\end{tabular}

trated sample. The relative biomass values of the main species found in the concentrated (>15 $\mu \mathrm{m})$, non-concentrated (natural population) and control $(<15 \mu \mathrm{m})$ samples are presented in Fig. 4. These samples consisted mainly of diatoms. Fragilaria cretonensis was the most abundant species in the concentrated samples, accounting for more than $50 \%$ of the total biomass. In the natural (non-concentrated) and control samples $F$. cretonensis only dominate in the data from Expt I. In the other 2 experiments the most abundant species were Chaetoceros sp. and Skeletonema costatum, which constituted more than $60 \%$ of the natural and control samples. From these experiments it appears that the concentration procedure increases the relative biomass value of the species F. cretonensis.

It is important to note that the maximal concentration factor (concentrated biomass/non-concentrated biomass) was about 20 , in the first experiment, and that a smaller concentration factor, about 3 , was found in the other 2 experiments. This is related to the fact that filtering properties of a net are in part determined by the species composition of the plankton. When chainforming species (e.g. Skeletonema costatum) or species with spines or setae (e.g. Chaetoceros spp.) are abundant in the natural sample the plankton itself may form a network inside the gauze, preventing a high concentration factor (UNESCO 1978). The number of damaged organisms found was very small, and there was no apparent relation between this number and sample concentration. However, it is difficult to ascertain whether a significant number of organisms can be destroyed by the use of this concentration net, because most of the phytoplankters identified were diatoms.

In Expt I the effect of the biomass pre-concentration on the rate of oxygen production and respiration was analysed. The results show that the production and consumption of oxygen were linearly correlated with the increase in chl a concentration (ANOVA, $p<0.05$ and ANOVA, p < 0.01, respectively) (Fig. 5).

It was not possible to measure the respiration rate when the chl a concentration was below $45 \mathrm{mg} \mathrm{m}^{-3}$. From these results it appears that concentrating the phytoplankton biomass does not affect specific oxygen production and consumption rates.

In Expt II natural phytoplankton samples were exposed to different light intensities. The GPP values obtained were fitted to 3 different mathematical models (Fig. 6) and the $P / I$ parameters were derived after fitting the data to these models using least-squares non-linear regression (Table 3 ).

The equations of Platt et al. (1980) and Eilers \& Peeters (1988) have a better fit than Steele's (1962) equation. The Eilers \& Peeters (1988) model was chosen since it is based on the physiology of photosynthesis. 

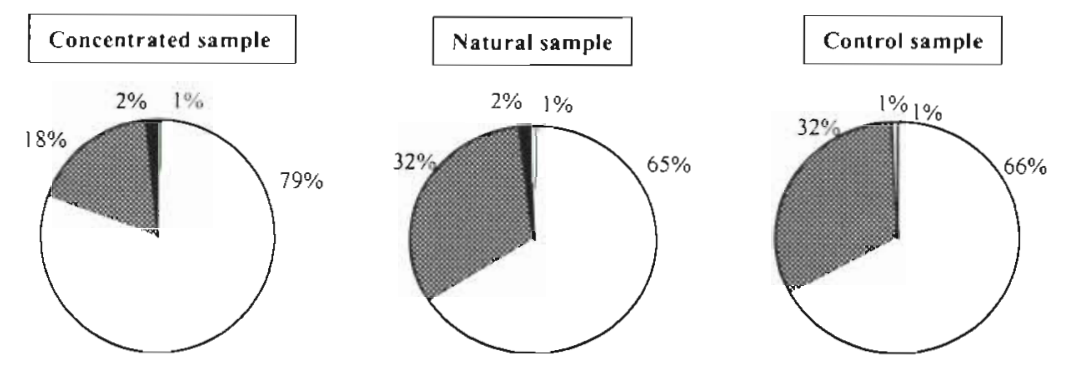

Date

Fragilaria cretonensis

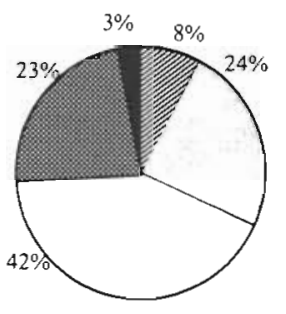

May 20

Melosira spp
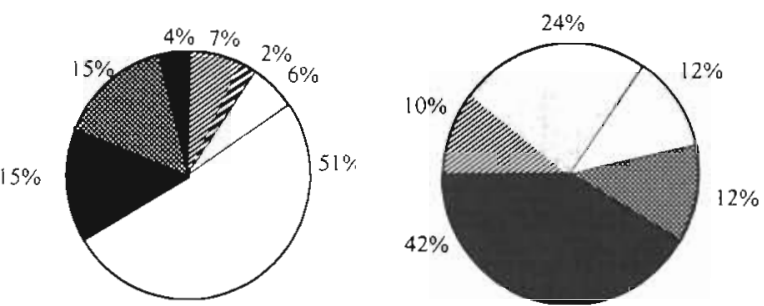

June 19
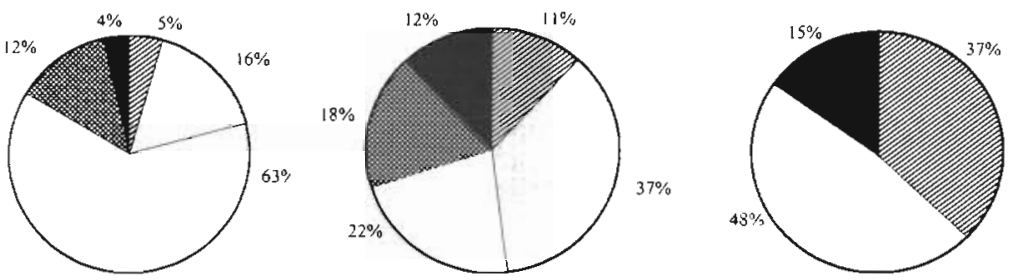

July 2

Fig. 4. Relative percentage of the main taxonomic groups found in the concentrated, non-concentrated ('Natural') and control samples. For May 20 , the $1 \%$ values in the concentrated and nonconcentrated samples are Asterionella formosa, and those in the control sample are $A$. formosa and Cyclotella meneghiniana

In Expt III concentrated water samples were exposed to 5 different light intensities for $15,45,90$ and 180 min. Fig. 7 shows the oxygen evolution over time at the light levels tested. The dissolved oxygen concentration in the water does not increase linearly with time, and at all the light intensities tested the slope is higher for the initial exposure time. It is also noted that for incubation periods longer than $45 \mathrm{~min}$ the oxygen evolution increases linearly with time, except for the results under highest light intensity.
From these data it appears that productivity is not just dependent on light intensity but also on exposure time, as reported by several authors (e.g. Marra 1978a, b, Neale \& Marra 1985, Falkowski \& LaRoche 1991, Franks \& Marra 1994). As oxygen production does not increase linearly with time, the production rate is not constant and cannot be estimated as the difference between the final and the initial value of oxygen concentration. To overcome this problem, the gross production rates were calculated for the partial time
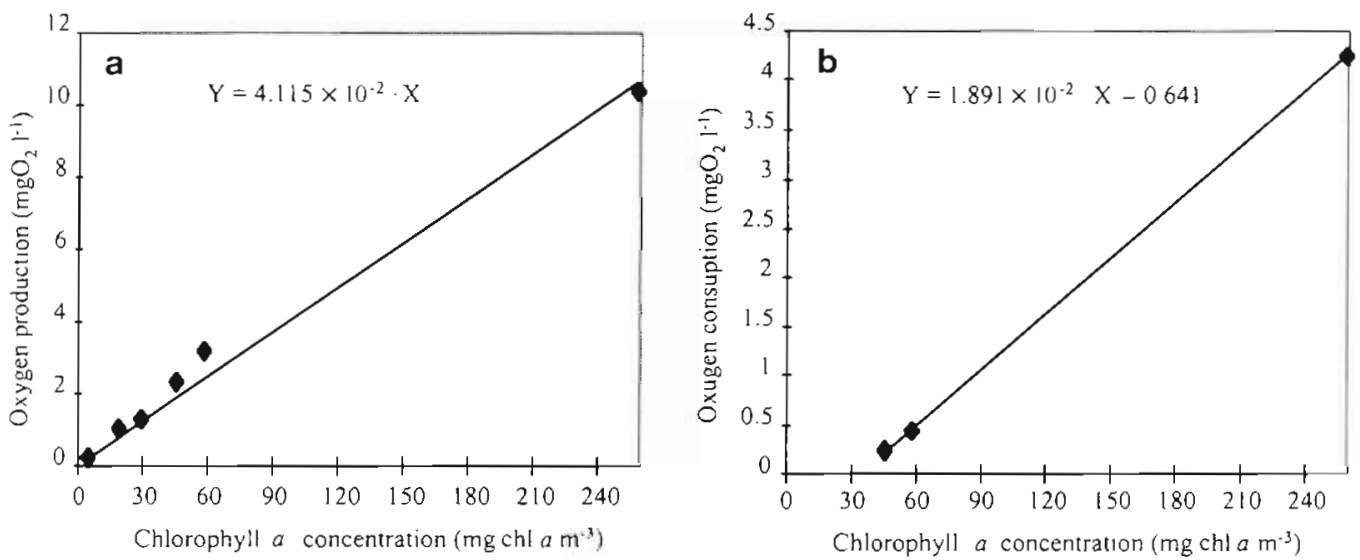

Fig. 5. Relation between chl a concentration and oxygen production (a) and consumption (b), obtained from Expt I. Each point represents the mean value of 3 replicates 
intervals $(0-15,15-45,45-90$ and $90-180$ min). The respiration rate was determined using 180 min of dark incubation. Since there was no data on respiration from shorter incubation periods, a constant respiration rate was assumed. The values obtained were fitted using the Eilers \& Peeters' (1988) equation (Fig. 8, Table 4).

This study was performed during early summer in a temperate zone. The high values of phytoplankton biomass shown in Table 2 reflect a well-known seasonal trend, with high values in spring-summer and low values in winter (Moita 1982, Cabrita \& Moita 1995, Macedo 1997). These biomass values are also a reflection of the considerable primary production rates occurring during this season. In fact, the $P_{\max }^{B}$ values found for incubation periods longer than 45 min (Table 4) fall in the upper range of the representative values, from 0.2 to $17 \mathrm{mg} \mathrm{C}(\mathrm{mg} \mathrm{chl} a)^{-1} \mathrm{~h}^{-1}$, proposed by Lalli \& Parsons (1993). For shorter incubation periods the $P_{\max }^{B}$ values reported were even higher. Table 5 presents maximal production rates of phytoplankton populations from different sites. From this table it can be seen that the maximum primary production values exhibit a very broad range.

The respiration rate found in this experiment $\left[1.8 \mathrm{mg} \mathrm{C}(\mathrm{mg} \mathrm{chl} \mathrm{a})^{-1} \mathrm{~h}^{-1}\right.$ ] ranged from 5 to $19 \%$ of the $P_{\max }^{B}$ value, depending on the incubation interval. This relation, $\mathrm{R} / P_{\max }^{B}$, falls within commonly quoted values, i.e. between 5 and $20 \%$.

From Fig. 8 it can be seen that short-time incubation resulted in a saturation curve instead of an inhibition curve. Photoinhibition needs time to develop and become measurable (Kok 1956, Harris \& Piccinin 1977, Marra 1978 a, b.

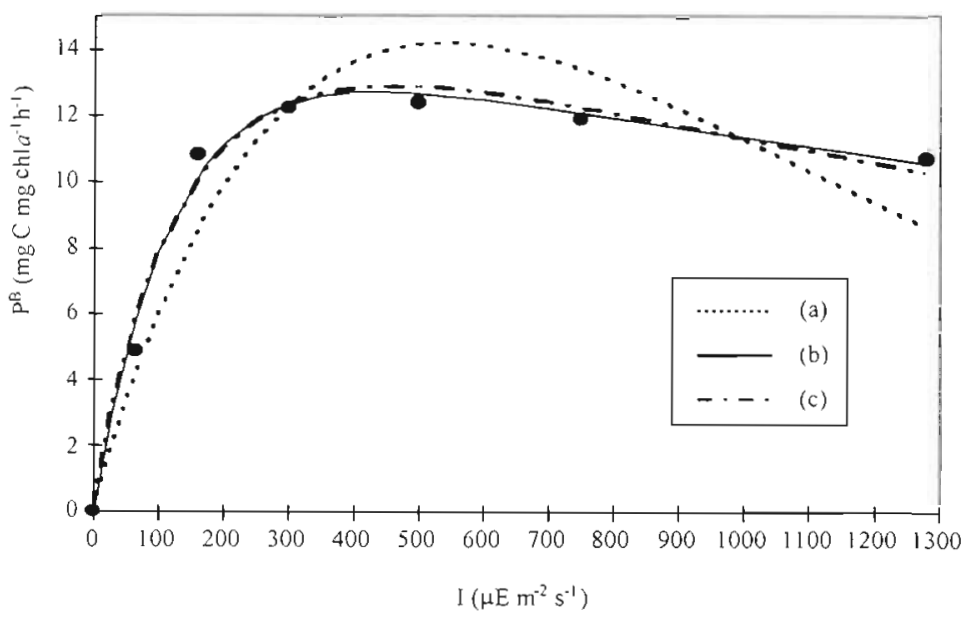

Fig. 6. Photosynthesis vs irradiance $(P / I)$ curves obtained after fitting the data with the Steele (1962) (a), Platt et al. (1980) (b) and Eilers \& Peeters (1988) (c) equations. Each point represents the mean value of 3 replicates obtained from a non-concentrated sample

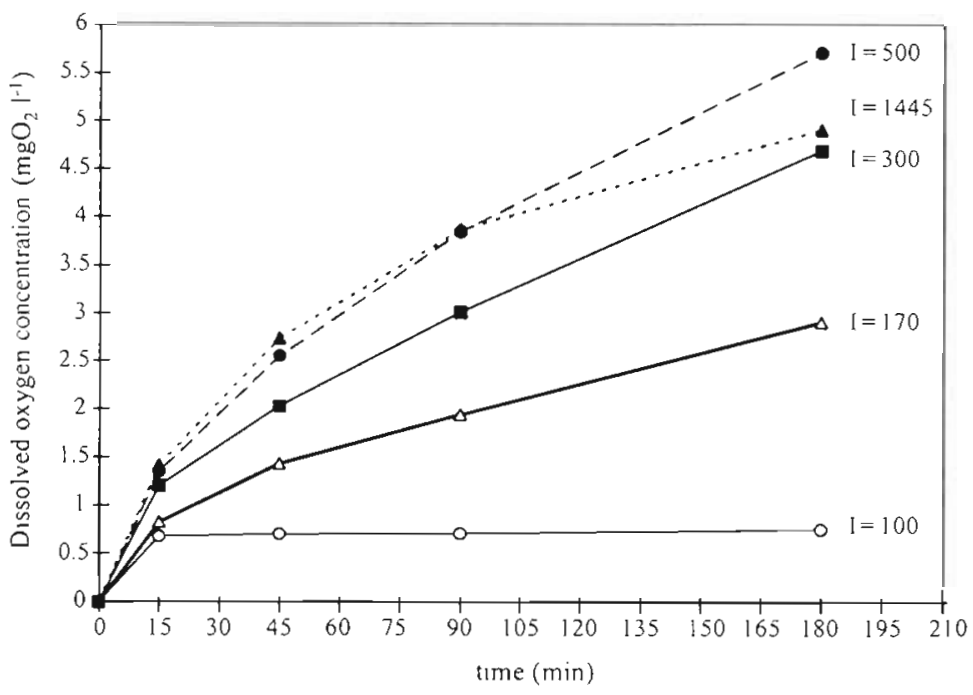

Fig. 7. Variation of the dissolved oxygen concentration during the incubation period at 5 different light intensities $\left(\mu \mathrm{E} \mathrm{m}^{-2} \mathrm{~s}^{-1}\right)$. Each point represents the mean value of 3 replicates obtained from a concentrated sample
Table 3. Parameters of the P/I curve obtained after fitting the data to the Steele (1962), Platt et al. (1980) and Eilers \& Peeters (1988) equations: $\alpha$, the initial slope of the light saturation curve $\left[\mathrm{mg} \mathrm{C}(\mathrm{mgchl} a)^{-1} \mathrm{~h}^{-1} \mu \mathrm{E}^{-1} \mathrm{~m}^{2} \mathrm{~s}\right)_{;} P_{\max }^{B}$, the maximal production rate $\left[\mathrm{mgC}(\mathrm{mgchla})^{-1} \mathrm{~h}^{-1}\right] ; I_{\text {opt, }}$ the optimal light intensity; and $I_{k}$, the light-saturation parameter $\left(\mu \mathrm{E} \mathrm{m}^{-2} \mathrm{~s}^{-1}\right)$

\begin{tabular}{|lccc|}
\hline $\begin{array}{l}\text { Parameters of } \\
\text { the P/I curves }\end{array}$ & $\begin{array}{c}\text { Steele } \\
(1962)\end{array}$ & $\begin{array}{c}\text { Platt et al. } \\
(\mathbf{1 9 8 0 )}\end{array}$ & $\begin{array}{c}\text { Eilers \& Peeters } \\
(1988)\end{array}$ \\
\hline$\alpha$ & 0.071 & 0.118 & 0.12 \\
$P_{\max }^{B}$ & 14.2 & 12.72 & 12.89 \\
$I_{\mathrm{opt}}$ & 544 & 433 & 565 \\
$I_{k}$ & 200 & 108 & 103 \\
ANOVA & $\mathrm{p}>0.05$ & $\mathrm{p}<0.05$ & $\mathrm{p}<0.05$ \\
\hline
\end{tabular}

Table 4. Parameters of the $P / I$ curve, for different incubation periods, obtained after fitting data to the Eilers \& Peeters (1988) model: $\alpha$, the initial slope of the light saturation curve $\left[\mathrm{mgC}(\mathrm{mgchl} a)^{-1} \mathrm{~h}^{-1} \mu \mathrm{E}^{-1} \mathrm{~m}^{2} \mathrm{~s}\right]_{;} P_{\max }^{B}$, the maximal production rate $\left[\mathrm{mg} \mathrm{C}(\mathrm{mg} \mathrm{chl} \mathrm{a})^{-1} \mathrm{~h}^{-1}\right] ; I_{\mathrm{opl}}$, the optimal light intensity; and $I_{k}$, the light-saturation parameter $\left(\mu \mathrm{E} \mathrm{m}^{-2} \mathrm{~s}^{-1}\right)$

\begin{tabular}{|lcccc|}
\hline & \multicolumn{5}{c}{ Incubation period (min) } \\
& $0-15$ & $15-45$ & $45-90$ & $90-180$ \\
\hline$\alpha$ & 0.259 & 0.052 & 0.029 & 0.03 \\
$P_{\max }^{B}$ & 36.3 & 18.7 & 13.8 & 9.65 \\
$I_{\mathrm{npt}}$ & 992 & 942 & 742 & 527 \\
$I_{k}$ & 140 & 336 & 474 & 316 \\
\hline
\end{tabular}




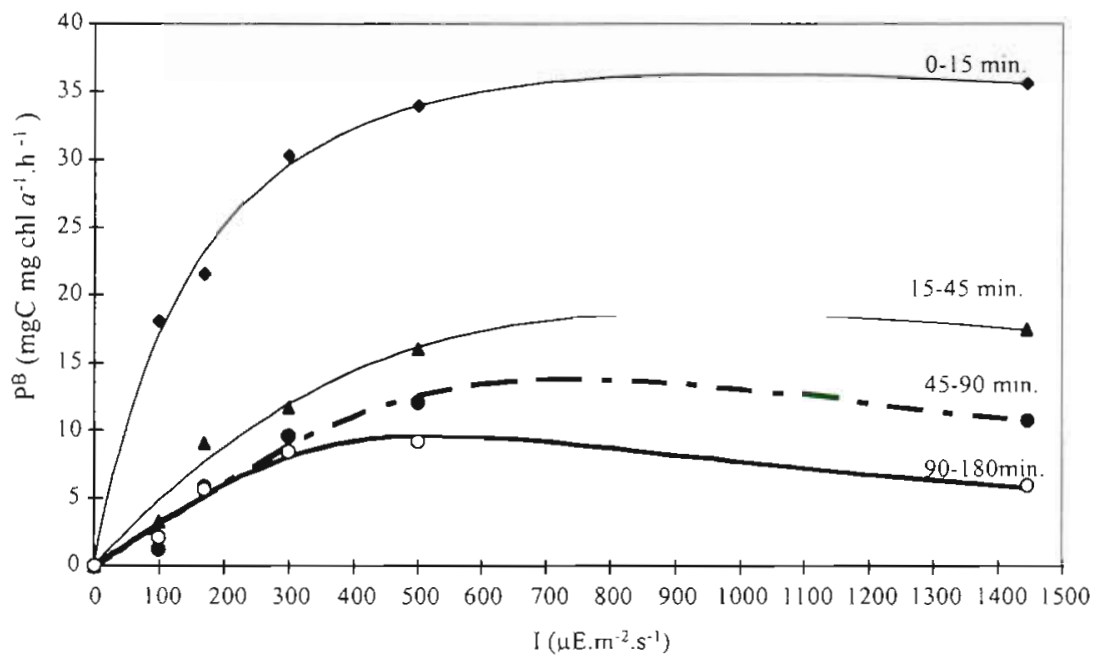

Fig. 8. Average productivity calculated from the time intervals $0-15,15-45$, 45-90, and 90-180 min. The P/I curves were obtained after fitting the data from different incubation times, with the Eilers \& Peeters (1988) model. Each point represents the mean value of 3 replicates obtained from a concentrated sample

Table 5. Values of maximum production rate, $P_{\max }^{B}[\mathrm{mgC}$ ( $\left.\mathrm{mgchl} a)^{-1} \mathrm{~h}^{-1}\right]$, of phytoplankton populations from different locations

\begin{tabular}{|c|c|c|}
\hline Source & Locations & $P_{\max }^{B}$ \\
\hline $\begin{array}{l}\text { Lalli \& Parsons } \\
\text { (1993) }\end{array}$ & Several & $0.2-17$ \\
\hline $\begin{array}{l}\text { Côté \& Platt } \\
\text { (1983) }\end{array}$ & $\begin{array}{l}\text { Bedford Basin, } \\
\text { Nova Scotia, Canada }\end{array}$ & $2.04-8.37$ \\
\hline $\begin{array}{l}\text { Savidge } \\
\text { (1988) }\end{array}$ & $\begin{array}{l}\text { Strangford Lough, } \\
\text { Northern Ireland }\end{array}$ & $0.28-20.48$ \\
\hline $\begin{array}{l}\text { Riegman \& } \\
\text { Colijn (1991) }\end{array}$ & North Sea & $0.80-35.80$ \\
\hline $\begin{array}{l}\text { Kromkamp \& } \\
\text { Peene (1995) }\end{array}$ & $\begin{array}{l}\text { Schelde Estuary, } \\
\text { The Netherlands }\end{array}$ & $0.50-18.80$ \\
\hline Present study & Tagus Estuary, Portugal & $9.56-36.30$ \\
\hline
\end{tabular}

Belay 1981, Whitelam \& Codd 1983). For short incubations, after the phytoplankton is kept in the dark, all the 'photosynthetic factories' (sensu Crill 1977) are in the resting state; when the cells are subsequently exposed to light, the equilibrium between the resting state and the activated state will be quickly established (Eilers \& Peeters 1988, 1993). This means that in a short incubation period there will be very few transitions from the activated state to the inhibited state, whereas when light intensity remains very high for a long time photoinhibition becomes progressively more important.

The photosynthetic rate decreases with time for all irradiance levels, as can be seen from the plot in Fig. 9. The greatest absolute reduction occurs at the higher light intensities; however, the greatest relative decrease happens at lower irradiances. The results follow a similar pattern to the ones observed experimentally by Marra (1978b) and predicted by the DYPHORA

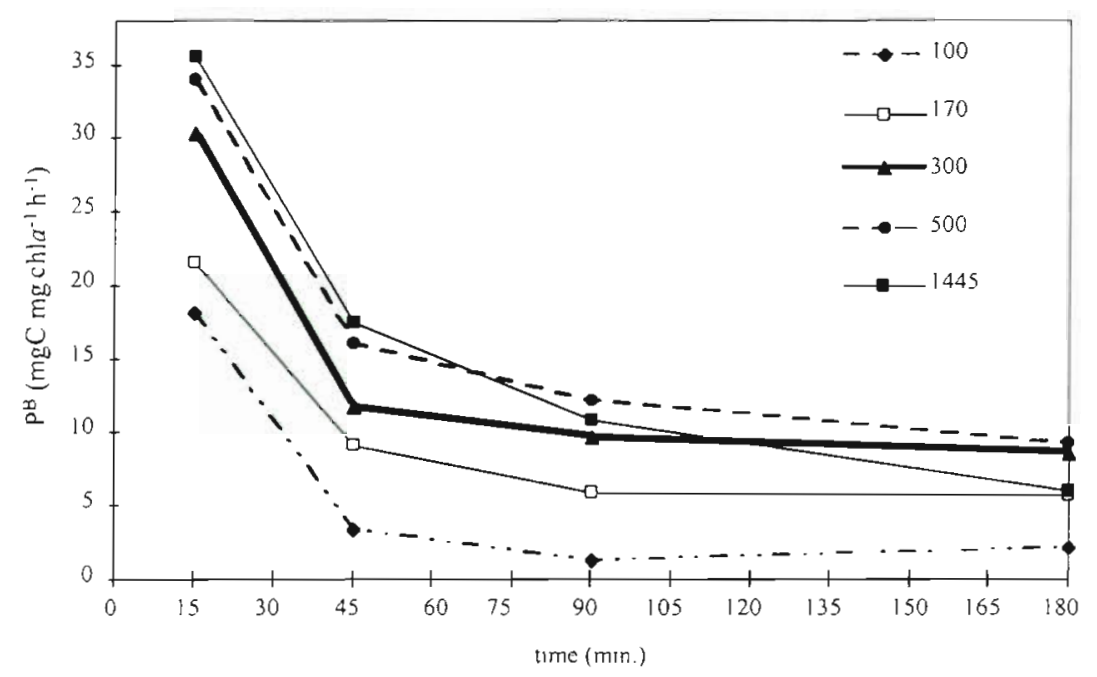

Fig. 9. Variation of production rate over time at 5 light levels $\left(\mu \mathrm{E} \mathrm{m}^{-2} \mathrm{~s}^{-1}\right)$. Each point represents the mean value of 3 replicates obtained from a concentrated sample 
model (Pahl-Wostl \& Imboden 1990). However, in Marra's (1978b) data, for irradiance levels lower than or equal to $150 \mu \mathrm{E} \mathrm{m} \mathrm{m}^{-2} \mathrm{~s}^{-1}$, the curve does not show a decrease with time. Since our data (Fig. 9) have only 1 light level below this value, it is not possible to predict if the photosynthetic rate will follow the same pattern for any given light intensity below $100 \mu \mathrm{E} \mathrm{m}^{-2} \mathrm{~s}^{-1}$.

In the present study a light inhibition decay time of about 1 to $2 \mathrm{~h}$ was found. This value falls in the range predicted by Pahl-Wostl \& Imboden (1990). The critical light intensity for onset of light inhibition must be below $100 \mu \mathrm{E} \mathrm{m}^{-2} \mathrm{~s}^{-1}$, since for all the light intensities tested the exposure time has an influence on the production rates.

From the previous results it seems that all the $P / I$ curve parameters are time-dependent. In some experiments it has been observed that after prolonged illumination with strong light, both $P_{\max }^{B}$ and the initial slope are reduced (Kok 1956, Steemann Nielsen 1962). Neale \& Marra (1985) pointed out that the variation of $P_{\max }^{B}$ should be considered as the primary source of time-dependence and Franks \& Marra (1994) present a non-linear time-dependent $P_{\max }^{B}$. A decrease in $I_{\text {opt }}$ with time was also observed for light intensities higher than the critical value. Henley (1993) gives examples of experiments conducted by other authors where a reduction in $\alpha$ occurs before any detectable change in $P_{\text {max }}^{B}$. Such a decrease is not clear from the data presented here, since the minimal light intensity used, $100 \mu \mathrm{E} \mathrm{m}^{-2} \mathrm{~s}^{-1}$, is too high for initial slope evaluation. Therefore only the $P_{\max }^{B}$ and $I_{\text {op }}$ parameters were assumed to be time-dependent. The variation of $P_{\max }^{B}$ and $I_{\text {opt }}$ with exposure time was analysed considering the centre of each time interval (Fig. 10).

The parameter $I_{\text {opt }}$ decreases linearly with incubation time. $P_{\max }^{\beta}$ can be related to time by a negative exponential function which reduces $P_{\max }^{B}$ until it reaches a constant, low value. This indicates that if phytoplankton is exposed to a critical irradiance for a short period of time, primary productivity may be higher than when measured after incubation of the phytoplankton for a few hours under the same light intensity. However, this relation implies an extremely high $P_{\max }^{B}$ value when the exposure time is zero, which is obviously false. In fact this equation predicts that, for short incubation periods, the $P_{\max }^{B}$ values increase with a decrease in the incubation time. But the experiments were performed for a minimum time of $15 \mathrm{~min}$, so prediction of values for lower incubation times would be an extrapolation. According to several authors (e.g. Harris \& Piccinin 1977, Pahl-Wostl \& Imboden 1990) a rapid increase in productivity, starting from zero, should be expected until the cells reach their full rate of photosynthesis, which must occur after 0.5 to $5 \mathrm{~min}$. This rapid increase in photosynthesis during the first few minutes is probably due to the activation of Rubisco (MacIntyre \& Geider 1996). According to these authors the rate at which photosynthesis is induced and reduced, due to increase and decrease of the irradiance, is limited by the kinetics of Rubisco activation and deactivation. Therefore, the equations presented here can only be used within the period tested.

A time-dependent model for the $P / I$ relationship was developed from the Eilers \& Peeters model. Using Eqs. (7) \& (8) and the relation found for the $P_{\max }^{B}$ and $I_{\text {opt }}$ varying with time, the following relation was established:

$$
P^{B}(I, t)=\frac{I}{c \frac{1}{\left[I_{\mathrm{opt}}(t)\right]^{2}} I^{2}+\left(\frac{1}{P_{\max }^{B}(t)}-c \frac{2}{I_{\mathrm{opt}}(t)}\right) I+c}
$$

$\left[\mathrm{mg} \mathrm{O}_{2}(\mu \mathrm{g} \mathrm{chl} \alpha)^{-1} \min ^{-1}\right]$

where the production rate is dependent on the light intensity and also on time.

Using Eq. (10) to describe the oxygen production rate, a model for the calculation of the dissolved oxy-
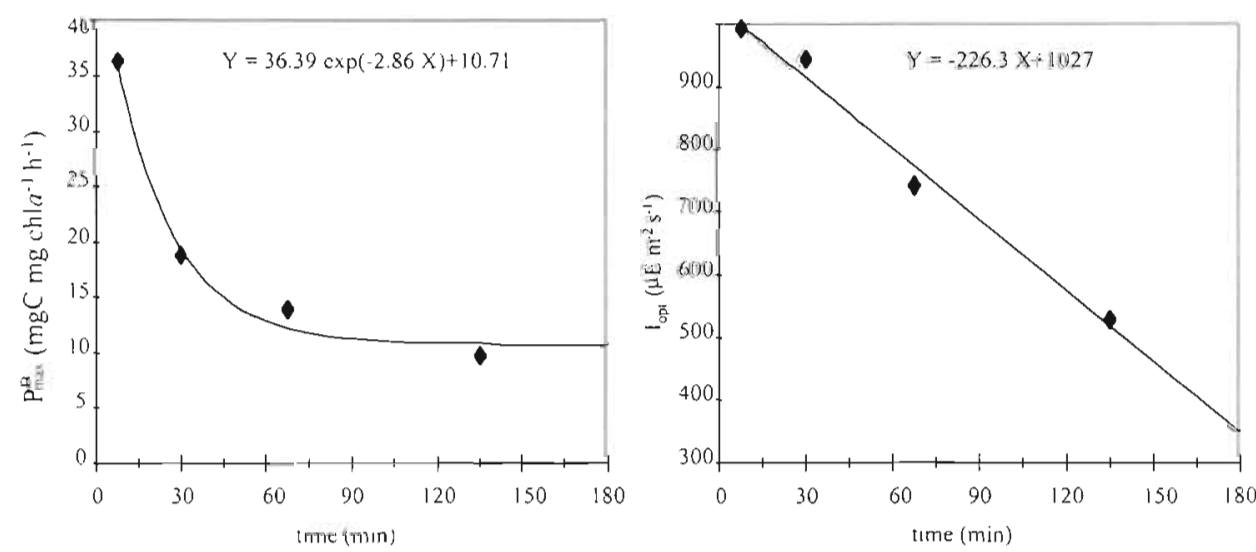

Fig. 10. Variation of $P_{\max }^{B}$ and $I_{\mathrm{op}}$ with exposure time 


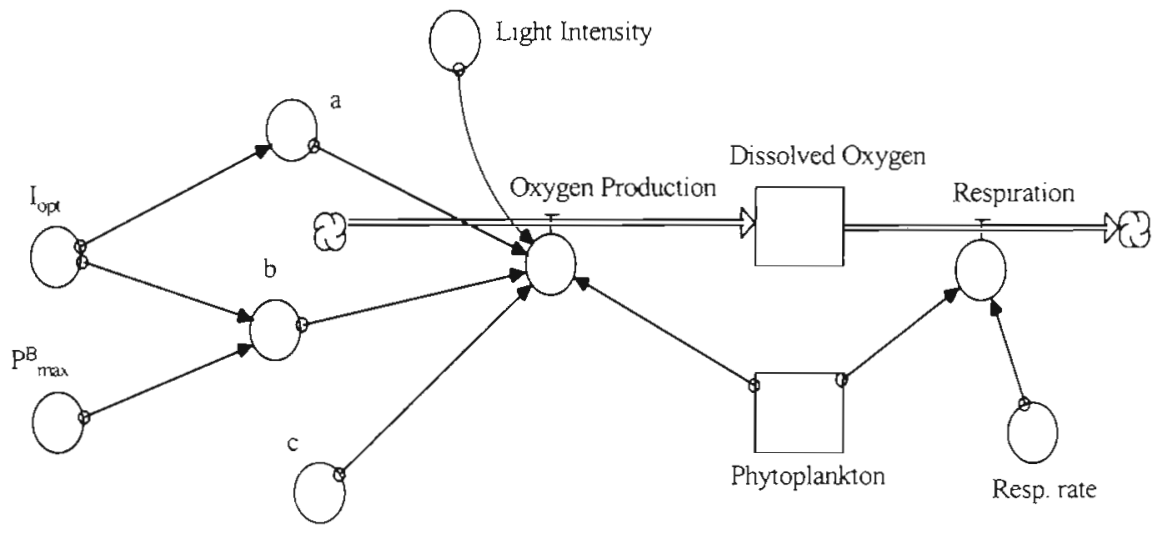

Fig. 11. Conceptual diagram of the dynamic dissolved oxygen model gen was built. The model was conceptualised as simply as possible, solely to investigate the importance of dynamic behaviour of oxygen production under different light intensities. The conceptual diagram of this model and the corresponding equations are presented in Fig. 11 and Table 6.

The relation between oxygen concentration predicted by this model and the observed data can be seen in Fig. 12. The simulation results indicate that the productivity function, $P^{B}(I, t)$, and the respiration rate used are adequate to describe the observed variation in oxygen concentration during the experiments.

If the productivity were determined solely from an incubation period of 0 to $180 \mathrm{~min}$ it would be accepted

Table 6. Equations of the dissolved oxygen model

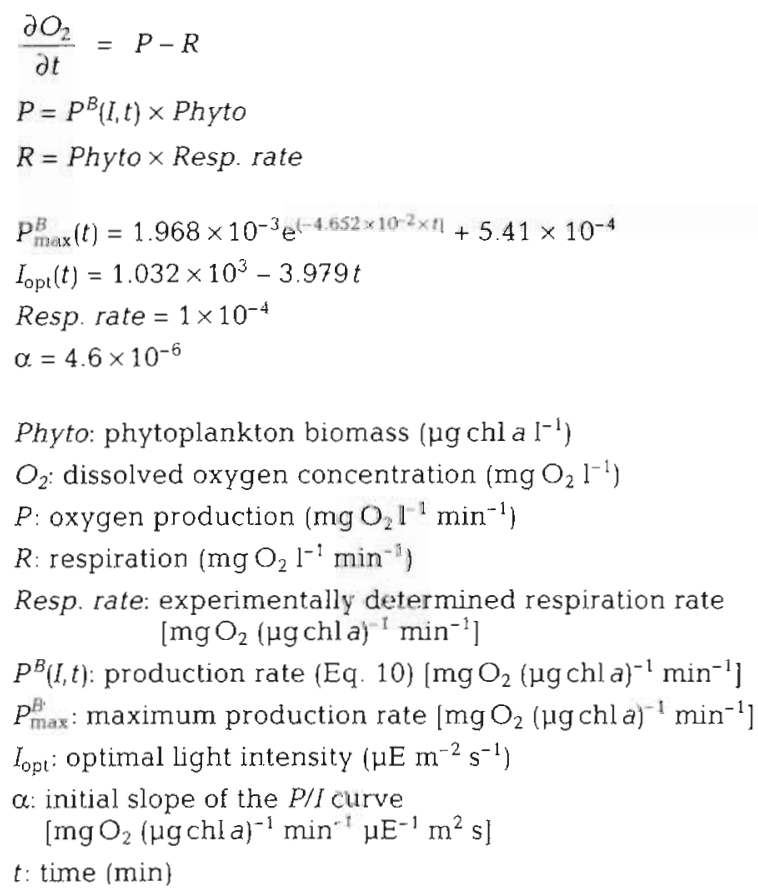

that the oxygen production increases linearly with time and productivity would be described as a static function, meaning that $P_{\max }^{B}$ and $I_{\text {opt }}$ values should be con-
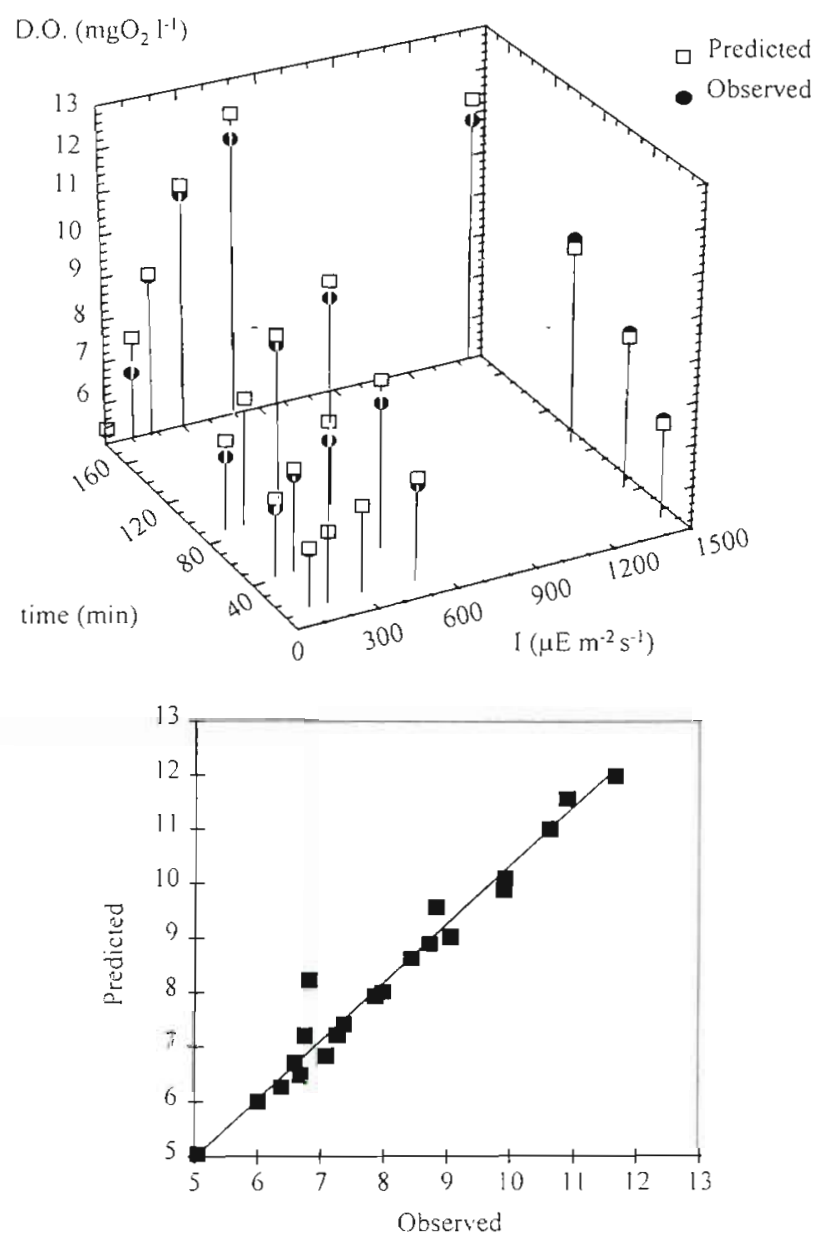

Fig. 12. Predicted and observed values of dissolved oxygen (D.O.) concentration. The slope of the regression line between observed and predicted values is not significantly different from 1 and the $y$-intercept is not significantly different from 0 $(p<0.05\}$ 

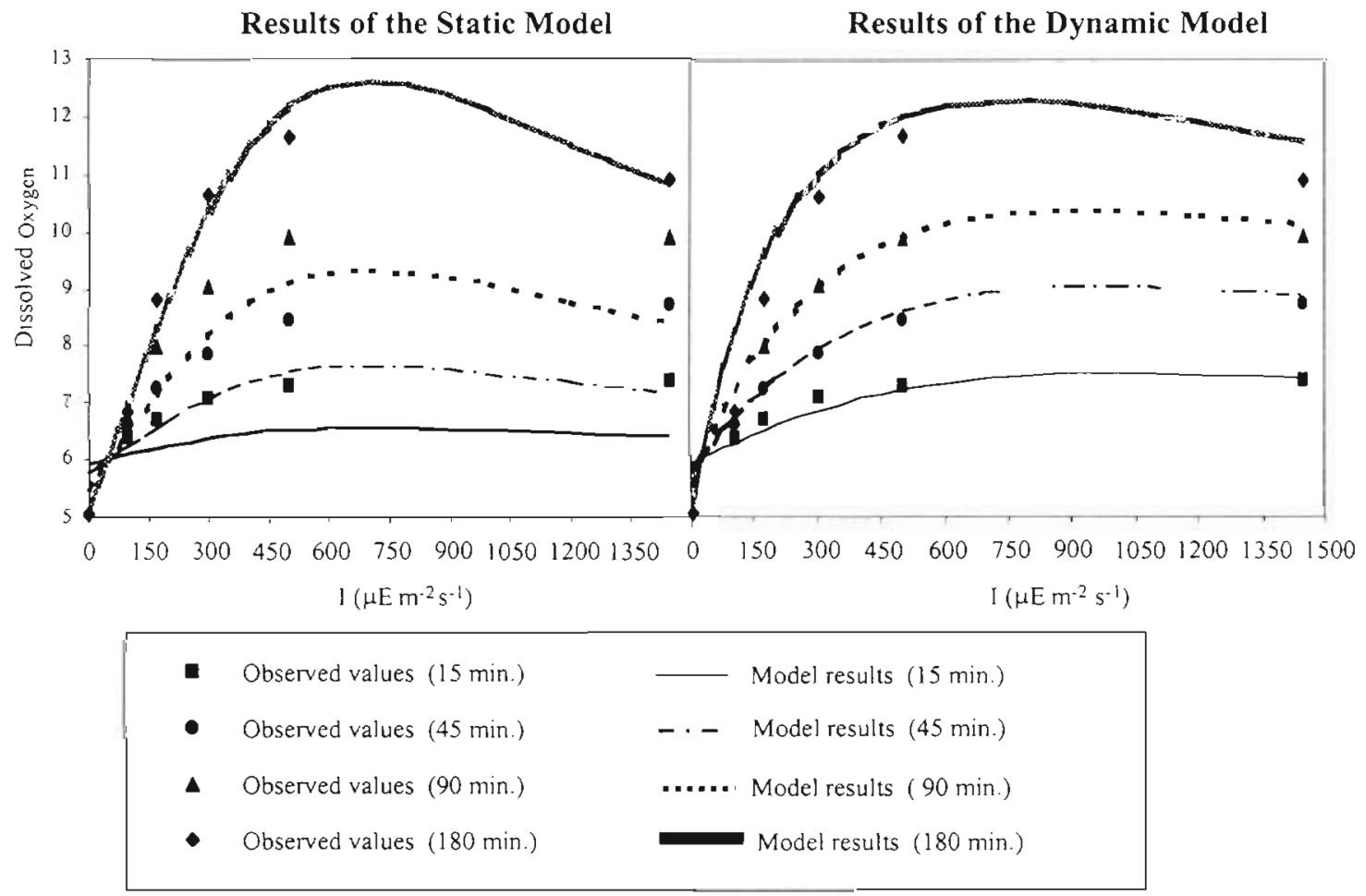

Fig. 13. Dissolved oxygen values $\left(\mathrm{mg} \mathrm{O}_{2} \mathrm{~L}^{-1}\right)$ predicted by the dynamic and static models plotted against the observed values

stant for any given time. In Fig. 13, the results obtained for static and dynamic simulations are compared and evaluated in the light of existing data.

As expected, the static model matches the observed values well when the $180 \mathrm{~min}$ curve is used. For incubation periods shorter than 180 min the static model underestimates the oxygen concentration. This underestimation is quite significant since the values predicted by the static model for $45 \mathrm{~min}$ are very close to the observed values for $15 \mathrm{~min}$; likewise, the $90 \mathrm{~min}$ static curve passes near the observed values for $45 \mathrm{~min}$ of incubation time. When strong vertical turbulence occurs, the time taken by a given phytoplanktonic cell to traverse the full gradient of irradiance in a $2 \mathrm{~m}$ water column is less than $180 \mathrm{~min}$, and the static formulation departs far from the real data.

This model gives a dynamic description of photosynthesis and photoinhibition using only 3 parameters that can be easily deduced from any $P / I$ curve. The $P_{\max }^{B}(t)$ and $I_{\mathrm{opl}}(t)$ equations are represented by simple equations (exponential and linear) which may be fitted to other sets of data. Furthermore, this model is based on a rational model of photosynthesis. One of its disadvantages is the assumption of a constant value for $\alpha$, which is probably not the most realistic approach. Another constraint is the absence of a parameter for the light activation of photosynthesis as described by other authors, e.g. Pahl-Wostl \& Imboden (1990) and MacIntyre \& Geider (1996). This parameter was not implemented here because the time resolution of our experimental data was not high enough to estimate the activation time.

\section{CONCLUDING REMARKS}

The main conclusion emerging from the simulations performed is that the dynamic behaviour of the production-light curves is relevant in the simulation of primary productivity, and that this is accentuated when short-term production is determined. Oxygen evolution through time was found to be non-linear, and the parameters $P_{\max }^{B}$ and $I_{o p t}$ were time-dependent. Shortterm (minutes to hours) variation in phytoplankton physiology is a general problem in the measurement and prediction of primary productivity in the surface mixed layer. When vertical mixing is considered, photoinhibition may be present at higher depths than without mixing, although surface inhibition is weaker than when mixing is absent. This is due to the downward transport of partially or fully inhibited cells (Duarte \& Ferreira 1997). The results show the impor- 
tance of redesigning the way primary productivity is usually measured by incubating water samples with phytoplankton for several hours at fixed depths.

The concentration procedure used in this study allowed the measurement of production rates by the oxygen method during short incubation periods. This method is easy to implement, is less expensive than the radioactive carbon method and allows the calculation of gross primary production and respiration. The use of this particular net design also has the advantage of decreasing the errors due to zooplankton respiration. From the results presented in this study it appears that concentration does not affect the production or respiration rates. However, the species diversity and composition may be more or less affected by the concentration procedure, depending on the species assemblage present. Further research needs to be done in order to improve and test this concentration methodology, but the results obtained are encouraging. This methodology can be very useful for primary production studies, particularly in areas of low productivity, for size-fractionation studies and short-term oxygenic photosynthesis studies, or when radioactive carbon cannot be used.

Acknowledgements. This research was supported by the PRAXIS XXI Program (MSc grant BM/534/94), the ECOTEJO project (JNICT PBIC/C/MAR/1293/92) and SOLVAY-Portugal. We thank F. J. Pina (New University of Lisbon) for helpful discussions and for making laboratory facilities available and $P$. Mendes for species composition analysis. The authors are also grateful to 4 anonymous referees for comments and helpful suggestions

\section{LITERATURE CITED}

Belay A (1981) An experimental investigation of inhibition of phytoplankton photosynthesis at lake surfaces. New Phytol 89:61-74

Cabrita MT, Moita MT (1995) Spatial and temporal variation of physico-chemical conditions and phytoplankton during a dry year in the Tagus Estuary (Portugal). Neth J Aquat Ecol 29(3-4):323-332

Carritt DE, Carpenter JH (1966) Comparison and evaluation of currently employed modifications of the Winkler method for determining dissolved oxygen in seawater; a NASCO Report. J Mar Res 24(3):286-318

Carvalho ML, Ferreira JG, Amorim P, Marques MIM, Ramos MT (1997) Study of heavy metals and other elements in macrophyte algae using energy-dispersive $X$-ray fluorescence. Environ Toxicol Chem 16(4):807-812

Cóté B, Platt T (1983) Day-to-day variations in the springsummer photosynthetic parameters of coastal marine phytoplankton. Limnol Oceanogr 28(2):320-344

Crill PA (1977) The photosynthesis-light curve: a simple analogue model. J Theor Biol 6:503-516

Cullen JJ, Lewis MR (1988) The kinetics of algal photoadapation in the context of vertical mixing. J Plankton Res 10: $1039-1063$

Denman KL, Gargett AE (1983) Time and space scales of vertical mixing and advection of phytoplankton in the upper ocean. Limnol Oceanogr 28(5):801-81.5

Dodson AN, Thomas WH (1964) Concentrating plankton in a gentle fashion. Limnol Oceanogr 9(3):455-456

Duarte P, Ferreira JG (1997). Dynamic modelling of photosynthesis in marine and estuarine ecosystems. Environ Mode] Assess 2:83-93

Eilers PHC, Peeters JCH (1988) A model for the relationship between light intensity and the rate of photosynthesis in phytoplankton. Ecol Model 42:199-215

Eilers PHC, Peeters JCH (1993) Dynamic behaviour of a model for photosynthesis and photoinhibition. Ecol Model 69:113-133

Falkowski PG, LaRoche J (1991) Minireview. Acclimation to spectral irradiance in algae. J Phycol 27:8-14

Falkowski PG, Wirick CD (1981) A simulation model of the effects of vertical mixing on primary productivity. Mar Biol 65:69-75

Ferreira JG, Ramos L (1989) A model for the estimation of annual production rates of macrophyte algae. Aquat Bot 33:53-70

Franks PJS, Marra J (1994) A simple new formulation for phytoplankton photoresponse and an application in a wind-driven mixed layer. Mar Ecol Prog Ser 111:143-153

Frenette JJ, Demers S, Legendre L, Dodson J (1993) Lack of agreement among models for estimating the photosynthetic parameters. Limnol Oceanogr 38(3):679-687

Gallegos CL, Platt T (1985) Vertical advection of phytoplankton and productivity estimates: a dimensional analysis. Mar Ecol Prog Ser 26:125-134

Geider RJ, Osborne BA (1989) Respiration and microalgal growth: a review of the quantitative relationship between dark respiration and growth. New Phytol 112: $327-341$

Harris GP, Lott JNA (1973) Light intensity and photosynthetic rates in phytoplankton. J Fish Res Bd Can 30:1771-1778

Harris GP, Piccinin BB (1977) Photosynthesis by natural phytoplankton populations. Arch Hydrobiol 59:405-457

Henley WJ (1993) Measurement and interpretation of photosynthetic light-response curves in algae in the context of photoinhibition and diel changes. J Phycol 29:729-739

Holm-Hansen O, Lorenzen CJ, Holmes RW, Strickland JDH (1965) Fluorometric determination of chlorophyll. J Cons Int Explor Mer 30:3-15

ICES (1996) Report of the working group on phytoplankton ecology. ICES CM/L:3. Biological Oceanography Committee. Ref: $C+E+E n v 28-30$

Iwakuma T, Yasumo M (1983) Comparison of several mathematical equations describing photosynthesis-light curve for natural phytoplankton populations. Arch Hydrobiol $97(2): 208-226$

Janowitz GS, Kamykowski D (1991) An Eulerian model of phytoplankton photosynthetic response in the upper mixed layer. J Plankton Res 13(5):988-1002

Jassby AD, Platt T (1976) Mathematical formulation of the relationship between photosynthesis and light for phytoplankton. Limnol Oceanogr 21(4):540-547

Jørgensen SE, Nielsen SN, Jørgensen LA (1991) Handbook of ecological parameters and ecotoxicology. Elsevier, London

Kok B (1956) On the inhibition of photosynthesis by intense light. Biochim Biophys Acta 21:234-244

Kromkamp J, Peene J (1995) Possibility of net phytoplankton primary production in the turbid Schelde Estuary (SW Netherlands). Mar Ecol Prog Ser 121:249-259

Lalli CM. Parsons TR (1993) Biological oceanography: an introduction. Butterworth-Heinemann Ltd, Oxford

Lewis MR, Cullen JJ, Platt I (1984) Relationships between 
vertical mixing and photoadaptation of phytoplankton: similarity criteria. Mar Ecol Prog Ser 15:141-149

Macedo MF (1997) Simulaçāo da produtividade primária fitoplanctónica. Aplicação à Cala do Norte do Estuário do Tejo. MSc thesis, Faculty of Sciences and Technology. New University of Lisbon

Maclntyre HL, Geider RJ (1996) Regulation of Rubisco activity and its potential effect on photosynthesis during mixing in a turbid estuary. Mar Ecol Prog Ser 144:247-264

MacIntyre S (1993) Vertical mixing in a shallow eutrophic lake: possible consequences of the light climate of phytoplankton. Limnol Oceanogr 38:798-817

Mallin MA, Paerl HW (1992) Effects of variable irradiance on phytoplankton productivity in shallow water Limnol Oceanogr 37:54-63

Marra J (1978a) Effect of short-term variations in light intensity on photosynthesis of marine phytoplankter: a laboratory simulation study. Mar Biol 46:191-202

Marra J (1978b) Phytoplankton photosynthetic response to vertical movement in mixed layer. Mar Biol 46:203-208

Marra J, Heinemann K (1982) Photosynthesis response by phytoplankton to sunlight variability. Limnol Oceanogr 27(6):1141-1153

Mergard RO, Tonkyo DW, Senft WH (1984) Kinetics of oxygenic photosynthesis in planktonic algae. J Plankton Res 6(2):325-337

Moita MT (1982) Estudo ambiental do Estuário do Tejo. Estudos dos pigmentos (clorofila a e feopigmentos) colhidos no estuário do Tejo em 1980. CNA/TEJO no. 15, Rel 14: $1-185$

Neale PJ, Marra $J$ (1985) Short-term variation of $P_{\max }$ under natural irradiance conditions: a model and its implications. Mar Ecol Prog Ser 26:113-124

Pahl-Wostl C, Imboden DM (1990) DYPHORA - a dynamic model for the rate of photosynthesis of algae. J Plankton Res 12:1207-1221

Peterson BJ (1980) Aquatic primary productivity and the ${ }^{14} \mathrm{C}$ $\mathrm{CO}_{2}$ method: a history of the productivity problem. Annu Rev Ecol Syst 11:359-389

Phillips JA (1973) Winkler method and primary production studies under special conditions. In: A guide to the measurement of marine primary production under some special conditions. UNESCO, Paris, p 48-54

Platt T, Gallegos CL, Harrison WG (1980) Photoinhibition of

Editorial responsibility: Otto Kinne (Editor),

Oldendorf/Luhe, Germany photosynthesis in natural assemblages of marine phytoplankton. J Mar Res 38:687-701

Pomeroy LR, Johannes RE (1968) Occurrence and respiration of ultraplankton in the upper 500 meters of the sea. Deep Sea Res 15:381-391

Randall JM, Day JW (1987) Effects of river discharge and vertical circulation on aquatic primary production in a turbid Louisiana (USA) estuary. Neth J Sea Res 21:231-242

Riegman R, Colijn F (1991) Evaluation of measurements and calculation of primary production in the Dogger Bank area (North Sea) in summer 1988. Mar Ecol Prog Ser 69: $125-132$

Savidge G (1988) Influence of inter-and intra-daily light-field variability on photosynthesis by coastal phytoplankton. Mar Biol 100:127-133

Steele JH (1962) Environmental control of photosynthesis in the sea. Limnol Oceanogr 7:137-150

Steemann Nielsen E (1962) Inactivation of the photochemical mechanism in photosynthesis as a means to protect cells against high light intensities. Physiol Plant 15:161-171

Strickland JDH, Parsons TR (1972). A practical handbook of sea water analysis, 2nd edn. Bull Fish Res Bd Can 167

Taguchi S (1976) Relationships between photosynthesis and cell size of marine diatoms. J Phycol 12(2):185-189

Takahashi M, Shimura S, Yamaguchi Y, Fujita Y (1971) Photoinhibition of phytoplankton photosynthesis as a function of the exposure time. J Oceanogr Soc Japan 27:43-50

Talling JF (1957) Photosynthetic characterisation of some freshwater plankton diatoms in relation to underwater radiation. New Phytol 56:29-50

UNESCO (1978) Phytoplankton manual. Muséum National d'histoire Naturelle, Paris

Vollenweider RA (1974) A manual on methods for measuring primary productivity in aquatic environments. Blackwell Scientific Publications, Oxford

Whitelam GC, Codd GA (1983) Photoinhibition of photosynthesis in the cyanobacterium Microcystis aeroginosa. Planta 157:561-566

Yentsch CS, Menzel DW (1963) A method for the determination of phytoplankton chlorophyll and phaeophytin by fluorescence. Deep Sea Res 10:221-231

Yoder JA, Bishop SS (1985) Effects of mixing-induced irradiance fluctuations on photosynthesis of natural assemblages of coastal phytoplankton. Mar Biol 90:87-93

Submitted: October 13, 1997; Accepted: January 28, 1998

Proofs received from author(s): April 22, 1998 